succession; while single and imperfect specimens are mere pitfalls. No imperfect or indistinct leaves, unless they possess exceptional characters, should be named, since however faithfully described or figured, they are simply confusing.

$$
\text { J. Stakkie Gardner. }
$$

\section{WIID SPAIN.1}

\section{$\mathrm{T}^{\mathrm{H}}$} HERE seems to be no limit in these days to the demand for books on popular natural history, especially when they combine a certain amount of science with a sporting element. The present volume, in which the authors endeavour to describe Spain from "a point of view hitherto almost unoccupied, that of the sportsman-naturalist," excellently illustrated as it is, will, no doubt, attract a host of readers, for it deserves to do so. One of the joint authors, Mr. Abel Chapman is already known to us as a writer on the bird-life of the Scotch Borders, and as an ornithologist who has laboured very successfully on the birds of spain. His coadjutor, Mr. Walter Buck, who is resident at Jerez, has long devoted himself to the exploration of the lower valley of the Guadalquivir and the bordering Sierras - the most interesting districts of the whole peninsula.

Although the larger mammals of Spain are by no means neglected, and even such extraneous subjects as corn, wine, oil, brigands and gypsies are cursorily treated of, "Wild Life in Spain" is emphatically a "bird-pook." After their digressions on other points the authors return to their feathered favourites with a zest which shows that the study of the bird-life of the peninsula, combined no doubt with an ardent love of "la chasse," was the primary object of their wanderings.

In the fauna of Wild Spain the abundance of the larger birds of prey forms a very prominent feature, and several chapters are well devoted to this part of the subject. Almost all the finest and largest Raptors of the European ornis are to be met with in Spain. To the ornithologist, who in these latter days may search the greater part of "Wild Britain" without finding anything more exciting than a stray kestrel or a fugitive sparrowhawk, this superabundance of the larger Falconidæ must prove a great attraction. Eagle-shooting, which would be a fearful crime in England, is allowable, if not praiseworthy, in the Spanish peninsula, and even an occasional vulture may be killed without much harm beirg done. Moreover Spain is fortunate in possessing an eagle of its own, called by modern naturalists Aquila adalberti, which is in fact a local form of the Imperial eagle of South-eastern Europe. But the Adalbert's eagle is remarkable as showing several successive stages of plumage which do not appear to occur in its near ally. On these we have much information in the present volume from actual experience, which seems to prove that the Spanish Imperial eagle breeds indiscriminately in its youthful and adult liveries, birds in fully adult plumage having been found paired with othes in the younger forms of dress. Besides eight or nine eagles two large vultures are abundant in the south of Spain, and the celebrated Lammergeier of the Alps known to the $A$ ndalucians by the appropriate name of "Quebranta huesos" or "bonesnatcher" is likewise still to be met with. How the eyries of this giant bird, situated in the mountains eastward of Jerez were visited and ransacked is told to us in two attractive chapters. As the breeding-season of the Lammergeier begins in January, when the Sierras are still under snow and the weather is inclined to be severe, such an expedition is by no means free from inconveniences.

Even in wild Spain, we regret to say, the Lammergeier

I "Wild Spain (Españ ı agreste), Records of Spo't with Rifle, Rod, and Gun, Natural History and Expl ration." By Abel Chapman, F.Z.S., and Walter J. Buck, C.M.Z.S., of Jerez. With 174 illu-trations, not cly
by the authors. (London: Gurney and Jackson, 1893. ) is yearly decreasing in numbers. "A decade ago they were fairly numerous in the vast area of rock-mountains which stretch between Granada and Jaen. To-day a week may be spent in that district without even so much as a distant view of this grand bird. The reason is unquestionably the use of poison, which is laid out broadcast by the goat-herds for the special benefit of wolves, but which is equally fatal to the Lammergeiers."

Another leading feature in the Spanish ornis is the Great Bustard, still abundant in Andalucia "on those vast stretches of silent corn-lands which form its home." "Big days with bustard," the various modes of its chasse and the principal features of its life are well described in "Wild Spain." It is curious that the authors do not seem to have been able to ascertain positively whether this bird is monogamous or polrgamous. Even during the pairing season each band of bustards is composed of mixed sexes, the females preponderating, until the latter skulk off to perform the duties of incubation, and leave the males all together in separate packs. Bustard-shooting must indeed be glorious sport. Ob, that Salisbury

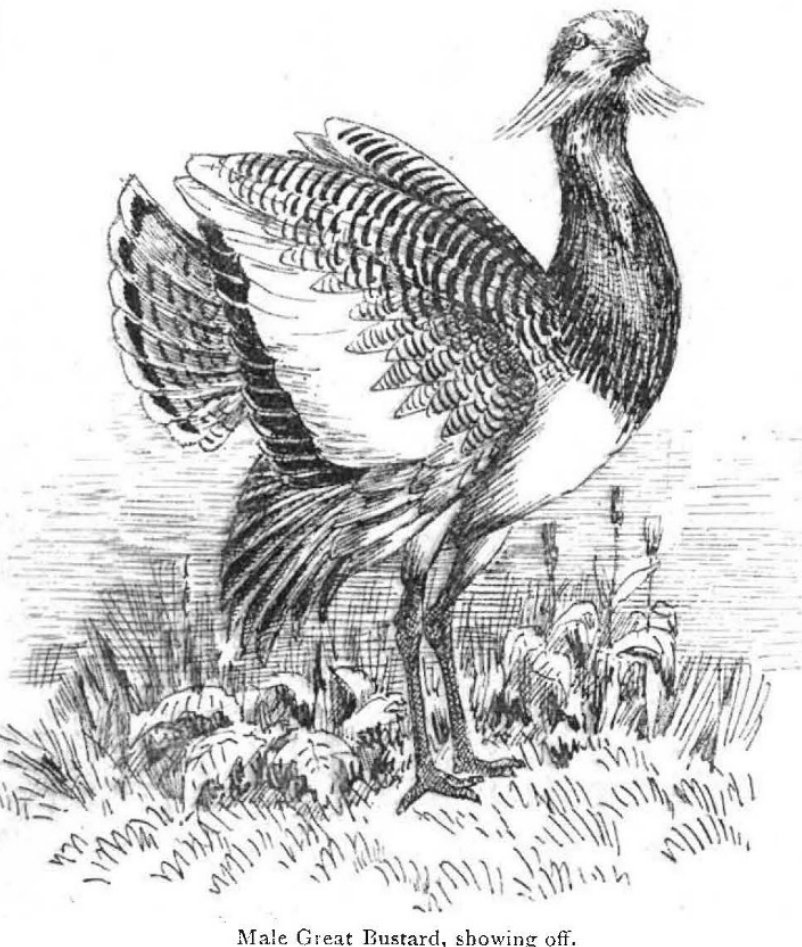

Plain could be restocked with this now nearly extinct (English) bird !

Next to the bustard the flamingo is perhaps one of the most attractive objects to the explorer of the wilds of Andalucia. In some seasons flamingoes visit the marismas in enormous flocks; in other years they are extremely scarce. In 1883 Mr. Chapman found them abundant in the month of Aprll, and searched the country over a large area systematically, in the hope of finding their breeding-places. The exact fashion in which this bird sits upon its nest had long been a matter of controversy, and it was hoped that this interesting point might now be definitely settled. But in April all etforts were unsurcessful-it was evident the birds had not yet begun to breed-and a smart attack of ague was the only result of splashing about from day to day in the mud and water, with a fierce sun beating down upon the ornithologist's head. In May, however, during an

NO. 1225 vOL. 47] 
exploration of certain bird-islets lying off the shore of the marisma, success was at length obtained. On a low mud-island was found a "perfect mass of nests," and scattered round the main colony were numerous single nests raised above the watcr-level. From a distance of about seventy yards the sitting birds were observed most distinctly. "The long red legs doubled under their bodies, the knees (scribe, heels) projecting as far as or beyond the tail, and their graceful necks neatly curled away among their back-feathers, with the heads resting on their breasts-all these points were unmistakable." The problem was thus solved, for it had been asserted by previous authorities that the sitting flamingo, unlike other birds, straddles across its elevated nest, leaving its long legs dangling down on each side! It is only fair, however, to add that the true in the marisma in a "wholly wild state," and are "practically ownerless."

Did space permit, we could well give further "elegant extracts" from this interesting volume, which is replete with information on the inhabitants of "Wild Spain," and their manners and customs. The numerous plates and smaller illustrations in the text are mostly excellent, and add greatly to the attractions of the work. We might, however, wonder that greater accuracy has not been secured as regards the spelling of some of the scientific names, especially when we are told that $\mathrm{Mr}$. Howard Saunders's experienced eye has "gone through the proofsheets. For example, Haliäetus is misprinted "Halizetus," Aëdon, "Edon," and Rhopalocera, "Rhodopalocera." Nor is it correct to call an Arabian camel (Camelus dromedarius) a "Bactrian" (i.e. C. bactrianus).

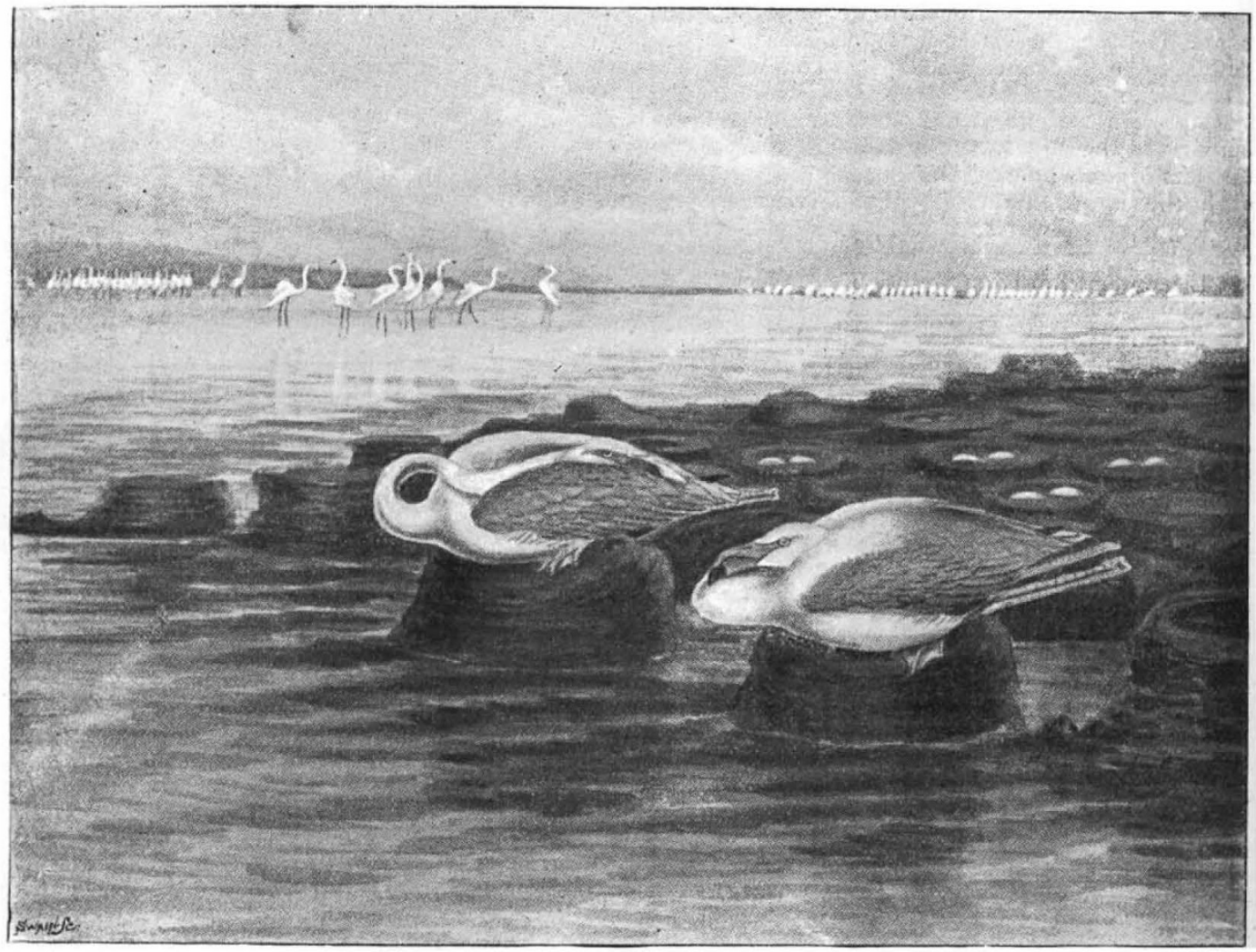

Flumingoes on their Nests.

mode of the incubation of the flamingo has also been witnessed since, in the case of the North American species (Phanicopterus roseus), by Sir F'enry Blake, in the West Indian island of Abaco (see Nineteenth Century, December, 1887). Sir Henry has fully confirmed the accuracy of $\mathrm{Mr}$. Chapman's observations.

Another curious discovery which we owe to the energy of Mr. Chapman is the existence of wild camels living and breeding in the "Bœtican Wilderness." The statement that camels were roaming about and reproducing their species in Europe at first met with nuch unbelief and even ridicule. There can be no doubt, however, on the subject. The camels were introduced from the Canaries in 1833 , and for some years used as beasts of burden in the province of Cadiz. At the present time some stray descendants of these camels live and flourish NO. 1225 , VOI. 47 ?
It is also now well known that the ichneumon of Spain is the same as the Algerian and Egyptian species (i.e. Herpestes ichneumon). It should therefore be no longer called Herpestes widdringtoni.

\section{NOTES.}

THE conditions under which the total solar cclipse on Sunday was observed seem, on the whole, to have been favourable. According to a telegram from Ceara, the clouds at Para Cura where the British expedition in charge of Mr. A. Taylor was stationed--were heavy before contact, but afterwards dispersed, leaving a clear space for observation during totality. The photographs were believed to be satisfactory. The eclipse was seen at Bathurs', in IV est Africa, " in perfectly clear 